\title{
Comparison of the Effectiveness of StyleWriter and Microsoft Word Computer Software to Improve English Writing Skills
}

\author{
Sunita Prvinchandar ${ }^{1} \&$ Ahmad Fauzi Mohd Ayub ${ }^{2}$ \\ ${ }^{1}$ SK Taman Universiti, Seri Kembangan, Selangor, Malaysia \\ ${ }^{2}$ Faculty of Educational Studies, Universiti Putra Malaysia, Malaysia \\ Correspondence: Ahmad Fauzi Mohd Ayub, Faculty of Educational Studies, Universiti Putra Malaysia, Malaysia. \\ E-mail: ahmad_fauzim@hotmail.com
}

\author{
Received: June 16, 2013 Accepted: October 15, 2013 Online Published: December 5, 2013 \\ doi:10.5539/elt.v7n1p93 URL: http://dx.doi.org/10.5539/elt.v7n1p93
}

\begin{abstract}
This study compared the effectiveness of two types of computer software for improving the English writing skills of pupils in a Malaysian primary school. Sixty students who participated in the seven-week training course were divided into two groups, with the experimental group using the StyleWriter software and the control group using the Microsoft Word programme. A pre-test was administered before the experiment was conducted. This was followed by post-tests upon completion of the course, where a computer-based assessment, as well as a pen-and-paper assessment, was employed. In each test, four components of writing skills were assessed, namely grammar, vocabulary, spelling, sentence structure, besides the overall performance. The findings indicated that the students who were exposed to StyleWriter had significantly better scores in all the writing components compared to the control group using Microsoft Word in both pen-and-paper and computer-based essay writing assessments. This study showed that StyleWriter enhanced the students' writing skills even when computer assistance was no longer available.
\end{abstract}

Keywords: computer assisted language learning (CALL), StyleWriter, Microsoft Word, English language learning

\section{Introduction}

The English language is commonly used among Malaysians even though it is not the official language of the country. In the Malaysian education system, English is taught as a compulsory second language (ESL), according to the Schools' Regulations of 1967 from the first year of the primary school till the final year in secondary school. The objectives of the English language curriculum for schools are to assist learners acquire the language for use in daily life, to pursue further education and improve their employability. In the present era of globalization, the English language plays a vital role in many aspects of our lives. Hence, it is important that students improve their proficiency in the language. The learning outcomes of the English language programmes in government schools are based on four basic language skills, viz. listening, speaking, reading and writing. Additional linguistic skills include the mastery of grammar, English pronunciation and the use of appropriate vocabulary. In the primary school curriculum, as it is essential to lay the foundation of learning the English language by emphasizing the basic skills.

Despite having been taught the English language throughout their schooling years, the mastery of the English language is a common problem among ESL students. Many ESL teachers admit that the majority of the students are weak at the language due to insufficient knowledge of grammar and vocabulary. As such, the students are not motivated to study English. When they feel that the lessons are too difficult to understand, they tend to lose interest in learning (Dornyei, 2003). When students fail to see the relationship between what they learn and real world activities, they also lose interest in their lessons (Mahdizadeh, 2006). Where writing in English is concerned, many students have difficulty even getting started. Such students dread writing and do not have a positive attitude towards this skill.

Many students lack self-confidence to write a good essay. They do not have background knowledge on certain topics in order to produce enough facts in their writing. Apart from that, according to some teachers, students doubt their ability to articulate their ideas clearly and correctly in terms of grammar, spelling, sentence structure 
and punctuation (Nunan, 2003). As such, students develop a fear of writing. They feel that everything they write is riddled with errors. These fears would only hold them back and often make their writing process even slower and ineffective. In addition, what usually happens in the English class is that teachers teach and students listen. This conventional way of teaching writing has been frowned upon as it does not encourage active interaction. Teachers are perceived as authoritative figures who are more concerned with obtaining the writing product rather than showing the students the process of writing. Therefore, Goesik (2004) suggests that teachers concentrate on teaching writing by using suitable resources or tools to improve students' writing performance. Writing is a complex process as it also encourages thinking. When students are confident of writing better, they will be more motivated to communicate. In the process of writing, these thoughts and ideas are re-evaluated, added to, reorganized or altered (Ghazi Ghaith, 2002).

Since the implementation of the Information and Communication Technology Literacy (ICTL) programme by the Ministry of Education in 1996 to boost the use of computer technology in education, most teachers have integrated the computer in their language lessons. This does not mean that non-ICT methods of teaching are no longer important. However, blending the use of technology with face-to-face instruction in teaching language skills such as listening, speaking, reading and writing facilitates the learning process (Forcier \& Descy, 2008). Computer-assisted instruction (CAI) or Computer Assisted Language Learning (CALL) refers to computerized teaching and learning. There are two principal features of CALL, viz. interactivity and learner independence (Schwienhorst, 2008). Computer programmes for writing outline main ideas, expand and arrange thoughts and ideas, as well as provide brainstorming. In other words, students could use computers to develop and practise their English language skills. They may develop critical thinking while attempting to execute learning tasks. Besides critical thinking, computer programmes also help students in creative analysis. For students to be creative thinkers, Haugland (1992) suggests that the educational software must be sufficiently easy to use by students. Such programmes should not only used in classrooms but also at home. According to Greany (2007), students who use software from the Internet are able to do tasks at a pace they are comfortable with. At home, students are able to monitor their learning progress by evaluating themselves as often as they want to. They make progress faster as they are constantly getting feedback and learning from it, they learn in private without peer competition, and learn when there is a need for it, and when they want to (Fenrich, 2005). Hence, by integrating technology in the English class, students can be guided to improve their writing skills. A good computer software encourages learner-centered education and helps students acquire competency in skill areas and facilitates lifelong learning. In the present digital age, teachers can avail themselves easily of numerous computer programmes to help learners master various skills such as writing, reading, listening and speaking. With regard to writing, students can use any kind of word-processor. Some versatile word-processors allow students to check spelling and find words in a thesaurus (Boswood, 1997). In the classroom setting, some computer programmes allow students to work in groups, and they can choose and control the activity throughout. Educational software also adapts itself to the progress of the student. As the student interacts with the programme, the system responds accordingly to provide feedback (Hohmann, 1998).

The effectiveness of using technologies in language teaching has been investigated. For example, Figueredo and Varnhagen (2006) conducted a study on the use of computer in teaching writing. By using computers, students were able to correct mistakes with the aid of spelling and grammar checkers. Therefore, the two researchers concluded that the use of spelling checkers was useful for weaker students who have poor writing skills. A study by Hartley, Sotto, and Pennebaker (2003) found out there were significant differences between the average letter length, the number of paragraphs written, and the number of sentences used by students who utilized computers and those who did not. There were also major differences in terms of readability, or typographical and grammatical errors. Besides using computer software, other software applications such as speech recognition, speech feedback, word prediction, and other varieties of software may help students with learning disabilities to participate in well-developed classroom writing programmes (Williams, 2002).

In Rowley and Meyer's (2003) study, the Computer Tutor for Writers (CTW) software was tested and evaluated on 471 students. The study results revealed that with the use of CTW, there was an improvement in the students' ability to follow a complete writing process, and they learned more than their peers did through conventional writing instruction. The effects of the computer tutor, known as HARRY, were analyzed by Holdich and Chung (2003) in their study which revealed that children who received conversational prompts from HARRY before, during, and after the writing wrote better stories compared to the classes which did not use HARRY. The children also believed that HARRY helped them manage their writing tasks. They were able to present different aspects of the writing process when requested. A study involving 40 young learners in Year 5 of a primary school in the state of Terengganu, Malaysia, was carried out by Faizah Mohamad and Nazeri Mohamad Amin (2009) with the 
aim of investigating whether a customized courseware which was specially developed for young learners was useful in teaching specific items of the English grammar. In their study, a quasi-experimental design was used on 20 learners. Their findings showed that, in general, the tailored courseware was useful in teaching grammar as students from the experimental group achieved better scores in their assessment on irregular and regular verbs.

An investigation of the effects of CALL on 60 English as a Foreign Language (EFL) learners' grammar competency was carried out by Mehrgan (2012). The results of his study obtained through a post-test revealed that the experimental group outperformed the control group. For that reason, CALL appeared to be useful in improving EFL students' English grammar. A similar study was conducted in Jordan by Abu Naba'h (2012) to examine the impact of using computer-assisted grammar teaching in the Jordanian EFL teaching context. The findings showed statistically significant differences on the mean scores on grammar which were attributed to the instructional technique. Students using the computer assisted grammar teaching programme had an edge over those who were taught using traditional instructional strategies.

Based on the earlier studies on CAI/CALL, there is a need to conduct a study to identify the effectiveness of suitable software to improve language skills. Instructors should explore various resources to improve learners' success in the English class. Many computer programmes are designed facilitate the teaching and learning of a language by integrating sounds, images and interactive settings, besides offering more information and a variety of exercises to reinforce learning. Hence, learning via computer software builds students' confidence; they become more independent of their teachers and are more accountable for their own learning. In short, students are more motivated to learn.

In this study we are comparing a two different types of writing softwares which are Microsoft word and also Stylewritter software. Both softwares are the independent variables while the dependent variables consist of students' performance in grammar, spelling, vocabulary and sentence structure. The StyleWriter software is the English Usage Checker. StyleWriter can be used for producing a variety of text types such as technical manuals, business letters, web site copy and many more (refer Figure 1). Errors are highlighted, and the StyleWriter is able to identify the writing faults, including ambiguous words, passive verbs, complex words, foreign words, overused words, qualifying words, jargon/abstract words, confused hyphens, gender-specific words, clichés, wordy phrases and legal words (refer Figure 2 and Figure 3). StyleWriter eliminates the old-fashioned writing practice by popping up recommendations and demonstrating to the learner how to edit each sentence.

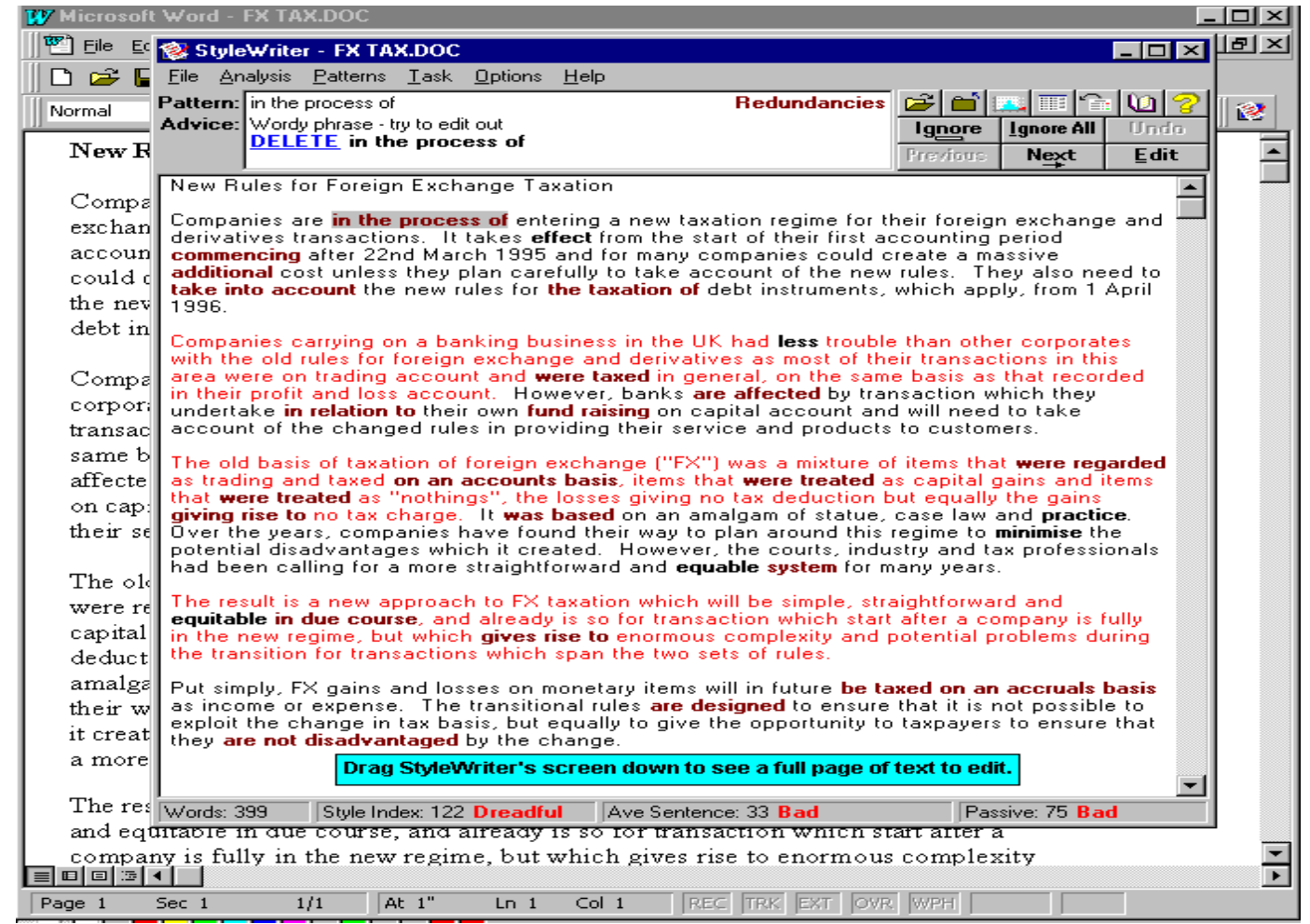

Figure 1. Screenshot of editing record 


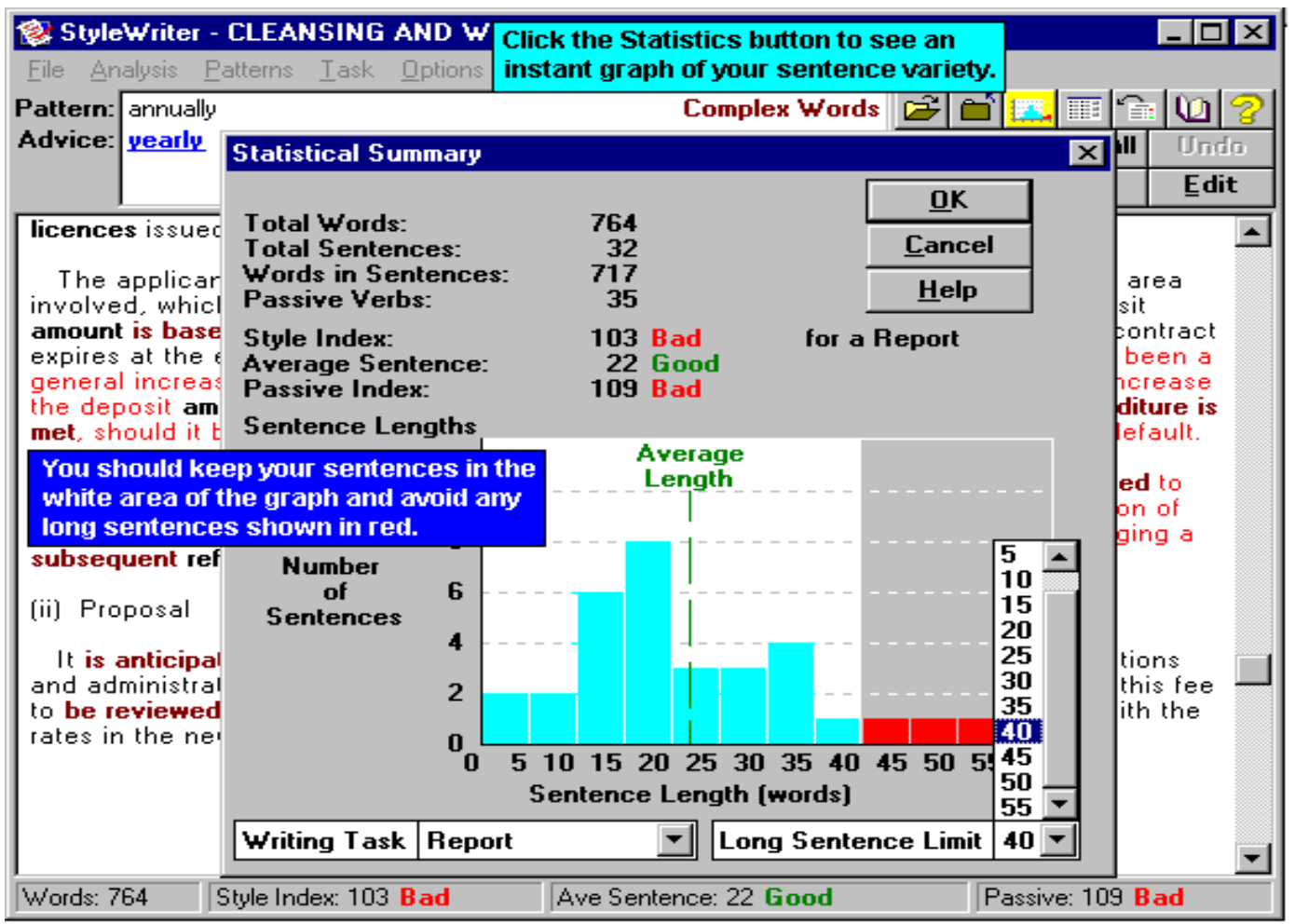

Figure 2. Screenshot of immediate graph of students' sentence variety

\begin{tabular}{|c|c|c|c|c|c|c|}
\hline $\begin{array}{l}\text { Q8 Style } \\
\text { File Ar }\end{array}$ & $\begin{array}{l}\text { aWriter - CLEANSING AND } \\
\text { alysis Patterns Task Opti }\end{array}$ & $\begin{array}{l}\text { JRKS Click the Categories but } \\
\text { Help a breakdown stye and }\end{array}$ & $\begin{array}{l}n \text { to se } \\
\text { age is: }\end{array}$ & es. & $-\square$ & \\
\hline Pattern: & annually & Complex words & $\ddot{\theta}$ & 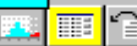 & 㪯: & 8 \\
\hline Advice: & yearly & & Ignore & Ignore All & IJnd & \\
\hline & & & Previous & Next & Edit & \\
\hline licence & es issued annually. & & & & & $\Delta$ \\
\hline Styl & Categories & Word usage c & heck fint & errors & tea & \\
\hline in $\mathbf{P}$ & lain English Style & word Usage & spellin & checker. & & \\
\hline e: & $35 \sqrt{V}$ Passive Verbs & $5 \sqrt{V}$ Misused Words & $\underline{0}$ & & een a & \\
\hline$g 6$ & $6 \sqrt{ }$ Hidden Verbs & $12 \sqrt{\square}$ Confused Words & $\underline{\text { Car }}$ & cel & $\begin{array}{l}\text { rease } \\
\text { ture is }\end{array}$ & \\
\hline $\mathbf{m}$ & $\begin{array}{l}19 \sqrt{ } \text { Complex Words } \\
2 \sqrt{ } \text { Jargon/Abstract }\end{array}$ & $\begin{array}{r}23 \sqcap \text { Confused Common } \\
1\lceil\text { Confused Hyphen }\end{array}$ & $\underline{\mathrm{H}}$ & & & \\
\hline $\begin{array}{l}\text { co } \\
\text { th }\end{array}$ & $\begin{array}{l}1 \sqrt{\nabla} \text { Overused Words } \\
\sqrt{\square} \text { Legal words }\end{array}$ & $\begin{array}{l}1 \sqrt{\nabla} \text { Hyphen Help } \\
\sqrt{\nabla} \text { Sexist Writing }\end{array}$ & & & $\begin{array}{l}\text { b to } \\
\text { pof } \\
\text { ng a }\end{array}$ & \\
\hline si & $\sqrt{ }$ Clichés & Г Sexist Common & Cabte & gory & & \\
\hline (ii & $7 \sqrt{\square}$ Redundancies & $4 \sqrt{V}$ Miscellaneous & All & & & \\
\hline ar & $1 \sqrt{ }$ Tautologies & Spelling & Get D & faults & $\begin{array}{l}\text { ons } \\
\text { his fee }\end{array}$ & - \\
\hline $\begin{array}{l}\text { to } \\
\text { ra }\end{array}$ & $1 \sqrt{ }$ Foreign words & $\sqrt{\square}$ Preferred Spelling & Set D & faults & & \\
\hline & $5 \sqrt{\checkmark}$ Sentence Check & $3 \sqrt{V}$ House Style & & & & \\
\hline $\begin{array}{l}\text { Editing } \\
\text { drama }\end{array}$ & $\begin{array}{l}\text { the plain English stye pu } \\
\text { ically changes the ways }\end{array}$ & $\begin{array}{l}\text { House Styl } \\
\text { organizatio }\end{array}$ & add yo & 4 int & $\begin{array}{l}\text { your } \\
\text { Writer. }\end{array}$ & \\
\hline Words: 7 & Style Index: $103 \mathrm{Bad}$ & Ave Sentence: 22 Good & & ssive: 109 & Bad & \\
\hline
\end{tabular}

Figure 3. Screenshot of types of writing habits 


\section{Objectives of the Study}

The main intention of this research was to compare the effectiveness of the use of two different types of writing software, namely Microsoft Word and StyleWriter. This study was specifically designed to meet the following objectives:

1) To compare students' performance in Computer-Based essay writing in classes using Microsoft Word and StyleWriter.

2) To compare students' performance in essay writing in lessons involving the use of the pen-and-paper method using Microsoft Word and StyleWriter software.

The following hypotheses were formulated to meet the research objectives:

$\mathrm{H}_{\mathrm{ol}}$. There is no significant difference in pre-test essay writing performance between students later involved in the use of Microsoft Word or StyleWriter.

$\mathrm{H}_{\mathrm{o2}}$. There is no significant difference in students' overall performance in computer-based essay writing assessments involving the use of Microsoft Word and StyleWriter.

$\mathrm{H}_{03}$. There is no significant difference in students' "grammar" performance in computer-based essay writing assessments between classes using Microsoft Word and StyleWriter.

$\mathrm{H}_{04}$. There is no significant difference in students' "spelling" performance in computer-based essay writing assessments between classes using Microsoft Word and StyleWriter.

$\mathrm{H}_{05}$. There is no significant difference in students" "vocabulary" performance in computer-based essay writing assessments between classes using Microsoft Word and StyleWriter.

$\mathrm{H}_{\mathrm{o6}}$. There is no significant difference in students' "sentence structure" performance in computer-based easy writing assessments between classes using Microsoft Word and StyleWriter.

$\mathrm{H}_{07}$. There is no significant difference in students' overall performances in essay writing assessments via pen-and-paper between classes using Microsoft Word and StyleWriter.

$\mathrm{H}_{\mathrm{og}}$. There is no significant difference on students' "grammar" performances in essay writing assessments via pen-and-paper between classroom using Microsoft Word and StyleWriter.

$\mathrm{H}_{09}$. There is no significant difference in students' "spelling" performances in essay writing assessments via pen-and-paper between classes using Microsoft Word and StyleWriter.

$\mathrm{H}_{\mathrm{o10}}$. There is no significant difference in students" "vocabulary" performances in essay writing assessments via pen-and-paper between classes using Microsoft Word and StyleWriter.

$\mathrm{H}_{011}$. There is no significant difference in students' "sentence structure" performance in essay writing assessments via pen-and-paper between classes using Microsoft Word and StyleWriter.

\section{Methodology}

This study used the pre-post-test quasi experimental design. Sixty Year 5 students of Sekolah Kebangsaan Taman Univeristi, a primary school in Seri Kembangan, Malaysia, participated in the 7-week course. Two classes were randomly selected. Students in the experimental group made use of the StyleWriter software, while the control group utilised Microsoft Word. The worksheet writing assessments, the primary evaluation instrument used in this research, consisted of the pre-test and the post-test questions. The tests examined five components of writing: grammar, spelling, vocabulary, sentence structure and overall performance. The main purpose of the pre-test was to determine the level of students' writing skill before the intervention. After seven weeks during which the experimental group used the StyleWriter, while the control group used Microsoft Word in their English lessons, post-tests were conducted for both groups to determine their progress. Both the tests (pre-test and post-test) were in the form of a guided essay, with picture prompts. For the post-test, a computer-based essay writing assessment was first employed, followed by the pen-and-paper (traditional) method of writing for both groups. For the computer-based writing assignment, the control group used the Microsoft Word programme while the experimental group students used the StyleWriter software.

\section{Findings}

The findings presented here are based on the 11 hypotheses proposed earlier. This study examined two computer-aided approaches to writing, involving either Microsoft Word or StyleWriter. The students' performances in writing were then assessed using both computer-based and traditional (pen-and-paper) methods. 


\subsection{Assessment of Students' Performance in Writing Prior to Computer-Aided Writing Course}

The first hypothesis examined the pre-test scores to evaluate students' writing skills. It was important that both groups had similar levels of writing skills before the intervention. An independent sample t-test was applied to determine whether there was any significant difference between the mean achievement scores of the experimental and control groups on the pre-test (at the level of significance equal to, or less than .05) in order to verify the following hypothesis.

$\mathrm{H}_{\mathrm{ol}}$. There is no significant difference in pre-test essay writing performance between students later involved in the use of Microsoft Word or StyleWriter.

Table 1. Independent sample t-test on the pre-test score in essay writing assessments

\begin{tabular}{lllllll}
\hline Group & $\mathrm{N}$ & Mean & $\mathrm{SD}$ & $\mathrm{T}$ & $\mathrm{Df}$ & $\mathrm{Sig}$ \\
\hline Control Goup (Microsoft Word) & 30 & 1.92 & .310 & & & \\
& & & & 1.586 & 58 & .118 \\
Experiment group (StyleWriter) & 30 & 2.07 & .415 & & & \\
\hline
\end{tabular}

The results of the pre-test are presented in Table 1, the mean scores of the experimental group $(M=2.07, S D=.415)$ and the control group $(M=1.92, S D=.310 ; t(58)=1.586, p=.118>.05)$. The difference between the means of the two treatments was not significant, hence supporting hypothesis $\left(\mathrm{H}_{\mathrm{ol}}\right)$. Overall, the results indicated that both groups had similar scores for their English essays before undertaking the computer-aided courses on writing.

\subsection{Assessment of Students' Performance in Computer-Based Writing}

The assessment was based on students' scores in grammar, spelling, vocabulary, sentence structure and overall performance. Table 2 below shows the variables incorporated in the study and means and standard of deviations.

Table 2. Independent sample t-test on the grammar, spelling, vocabulary, sentence structure and overall performance score in computer based essay writing assessment

\begin{tabular}{|c|c|c|c|c|c|c|c|}
\hline Hypotheses & Groups & $\mathrm{N}$ & Mean & $\mathrm{SD}$ & $\mathrm{T}$ & df & Sig \\
\hline $\mathrm{H}_{\mathrm{o} 2}:$ & Control group (Microsoft Word) & 30 & 3.17 & .461 & \multirow{3}{*}{7.154} & \multirow{3}{*}{58} & \multirow{3}{*}{.000} \\
\hline \multirow{2}{*}{$\begin{array}{l}\text { Grammar } \\
\text { Performance }\end{array}$} & & & & & & & \\
\hline & Experiment group (StyleWriter) & 30 & 4.23 & .626 & & & \\
\hline $\mathrm{H}_{03}:$ & Control group (Microsoft Word) & 30 & 3.23 & .430 & \multirow{3}{*}{9.707} & \multirow{3}{*}{58} & \multirow{3}{*}{.000} \\
\hline \multirow{2}{*}{$\begin{array}{l}\text { Spelling } \\
\text { Performance }\end{array}$} & & & & & & & \\
\hline & Experiment group (StyleWriter) & 30 & 4.40 & .498 & & & \\
\hline $\mathrm{H}_{04}:$ & Control group (Microsoft Word) & 30 & 3.33 & .479 & \multirow{3}{*}{9.143} & \multirow{3}{*}{58} & \multirow{3}{*}{.000} \\
\hline \multirow{2}{*}{$\begin{array}{l}\text { Vocabulary } \\
\text { Performances }\end{array}$} & & & & & & & \\
\hline & Experiment group (StyleWriter) & 30 & 4.50 & .509 & & & \\
\hline $\mathrm{H}_{05}:$ & Control group (Microsoft Word) & 30 & 3.43 & .568 & \multirow{3}{*}{8.758} & \multirow{3}{*}{58} & \multirow{3}{*}{.000} \\
\hline \multirow{2}{*}{$\begin{array}{l}\text { Sentence Structure } \\
\text { Performances }\end{array}$} & & & & & & & \\
\hline & Experiment group (StyleWriter) & 30 & 4.63 & .490 & & & \\
\hline $\mathrm{H}_{\mathrm{o} 6}$ : & Control group (Microsoft Word) & 30 & 3.29 & .219 & \multirow{3}{*}{20.11} & \multirow{3}{*}{58} & \multirow{3}{*}{.000} \\
\hline \multirow{2}{*}{$\begin{array}{l}\text { Overall } \\
\text { Performance }\end{array}$} & & & & & & & \\
\hline & Experiment group (StyleWriter) & 30 & 4.44 & .224 & & & \\
\hline
\end{tabular}

Test scores for grammar were compared for the two groups. Grammar refers to the set of complex rules in a language that determines meaningful use and combination of words in sentences. Thus, it is important for students to learn to write grammatically correct sentences. The independent sample t-test showed a significant 
difference in the mean score of the students in the control group $(\mathrm{M}=3.17, \mathrm{SD}=.461)$ and the experimental group $(\mathrm{M}=4.23, \mathrm{SD}=.626 ; \mathrm{t}(58)=7.154 ; p=.00<.05)$. Therefore the second hypothesis $\left(\mathrm{H}_{02}\right)$ was not supported. The result showed that after the training course, the students who employed the StyleWriter software achieved better scores in the grammar component compared to those who used Microsoft Word.

To write well, students in this study had to use words that were spelt correctly in order to obtain a good grade. Table 2 indicates that there was a significant difference between the control group's mean score $(M=3.23$, $\mathrm{SD}=.430)$ and the experimental group's mean score $(\mathrm{M}=4.40, \mathrm{SD}=0.498 ; \mathrm{t}(58)=9.707 ; p=.00<.05)$. Therefore, the third hypothesis $\left(\mathrm{H}_{03}\right)$ was not supported. This shows that by using StyleWriter software, students in the experimental group were able to employ the correct spelling when writing their essay, compared to the students who made use of Microsoft Word for writing.

The third component in the writing assessment is vocabulary. As illustrated in Table 2, the results of the t-test in vocabulary showed that there was significant difference between the control group $(\mathrm{M}=3.33, \mathrm{SD}=4.79)$ and the experimental group $(\mathrm{M}=4.50, S D=.509 ; \mathrm{t}(58)=9.143, p=.00<.05)$. The result indicated that hypothesis four $\left(\mathrm{H}_{04}\right)$ was not supported. StyleWriter had a positive effect on students' achievement in using correct or appropriate vocabulary in their writing as the software offers recommendations on distorted and confused words, hyphenation as well as many other troublesome words.

The final component in the writing assessment was the sentence structure. The results of the independent sample t-test showed that there was a significant difference in the achievement scores on "sentence structure" between the control group $(\mathrm{M}=3.43, \mathrm{SD}=.568)$ and the experimental group $(\mathrm{M}=4.63, \mathrm{SD}=.490 ; \mathrm{t}(58)=8.758, p=.00$ $<.05)$. This means that hypothesis five $\left(\mathrm{H}_{05}\right)$ was not supported. This result suggests that the StyleWriter software had a significant positive effect on the students' ability to construct meaningful sentences compared to the students who used Microsoft Word. For the overall performance, the results of the study indicated that there was a significant difference between the experimental group $(\mathrm{M}=4.44, \mathrm{SD}=.224)$ and their counterparts in the control group $(\mathrm{M}=3.29, \mathrm{SD}=.219 ; \mathrm{t}(58)=20.11, p=.000<.05)$. Thus hypothesis six $\left(\mathrm{H}_{06}\right)$ was not supported as the experimental group attained better scores in the writing assessment compared to those using Microsoft Word.

\subsection{Assessment of Students' Performance in Pen-and-Paper Writing}

For the second writing assessment, students needed to write a story about an incident with the help of a picture and word prompts in a pen-and-paper mode.

Table 3. Independent sample t-test on the grammar, spelling, vocabulary, sentence structure and overall performance scores in pen and paper mode essay writing assessments

\begin{tabular}{|c|c|c|c|c|c|c|c|}
\hline Hypotheses & Groups & $\mathrm{N}$ & Mean & SD & $\mathrm{T}$ & df & Sig \\
\hline $\mathrm{H}_{\mathrm{o} 7}:$ & Control group (Microsoft Word) & 30 & 2.00 & .371 & \multirow{3}{*}{9.786} & \multirow{3}{*}{58} & \multirow{3}{*}{.000} \\
\hline \multirow{2}{*}{$\begin{array}{l}\text { Grammar } \\
\text { Performance }\end{array}$} & & & & & & & \\
\hline & Experiment group (StyleWriter) & 30 & 3.37 & .669 & & & \\
\hline $\mathrm{H}_{08}:$ & Control Group (Microsoft Word) & 30 & 1.90 & .403 & \multirow{3}{*}{10.49} & \multirow{3}{*}{58} & \multirow{3}{*}{.000} \\
\hline \multirow{2}{*}{$\begin{array}{l}\text { Spelling } \\
\text { Performance }\end{array}$} & & & & & & & \\
\hline & Experiment group (StyleWriter) & 30 & 3.23 & .568 & & & \\
\hline $\mathrm{H}_{09}$ : & Control group (Microsoft Word) & 30 & 2.00 & .743 & \multirow{3}{*}{8.762} & \multirow{3}{*}{58} & \multirow{3}{*}{.000} \\
\hline \multirow{2}{*}{$\begin{array}{l}\text { Vocabulary } \\
\text { Performance }\end{array}$} & & & & & & & \\
\hline & Experiment group (StyleWriter) & 30 & 3.50 & .572 & & & \\
\hline $\mathrm{H}_{\mathrm{o} 10}:$ & Control group (Microsoft Word) & 30 & 2.13 & .730 & \multirow{3}{*}{7.24} & \multirow{3}{*}{58} & \multirow{3}{*}{.000} \\
\hline \multirow{2}{*}{$\begin{array}{l}\text { Sentence Structure } \\
\text { Performance }\end{array}$} & & & & & & & \\
\hline & Experiment group (StyleWriter) & 30 & 3.40 & .621 & & & \\
\hline $\mathrm{H}_{\mathrm{o} 11}:$ & Control group (Microsoft Word) & 30 & 2.01 & 402 & \multirow{3}{*}{12.50} & \multirow{3}{*}{58} & \multirow{3}{*}{.000} \\
\hline \multirow{2}{*}{$\begin{array}{l}\text { Overall } \\
\text { Performance }\end{array}$} & & & & & & & \\
\hline & Experiment group (StyleWriter) & 30 & 3.38 & .444 & & & \\
\hline
\end{tabular}


The first component measured in the pen and pencil essay writing assessment was correct grammar usage by the two groups. As can be seen in Table 3, there was a significant difference in the scores between the control group using Microsoft Word and experimental group which used StyleWriter. The experimental group scored significantly higher scores $(\mathrm{M}=3.37, \mathrm{SD}=.669)$ compared to the control group $(\mathrm{M}=2.00, \mathrm{SD}=.371 ; \mathrm{t}(58)=$ $9.786, p=.000<.05)$. Therefore, the hypothesis seven $\left(\mathrm{H}_{07}\right)$ was not supported. The finding indicated that students using StyleWriter achieved better scores in the grammar component during the pen and paper mode essay writing assessment compared to the students who used Microsoft Word.

The second component that was examined was the spelling scores in the paper mode essay writing assessment. The table above indicates that there was a significant difference between the control $(M=1.90, S D=.403)$ and the experimental group $(M=3.23, S D=.568 ; t(58)=10.49, p=.000<.05)$. Hypothesis eight $\left(\mathrm{H}_{08}\right)$ was not supported as the results showed that using StyleWriter helped students score higher marks in the spelling component.

For the vocabulary component, a comparison of the mean scores of the two groups showed that the mean score of the experimental group $(M=3.50, S D=.572)$ was significantly higher than that of the control group $(M=$ $2.00, S D=.743 ; t(58)=8.762, p=.000<.05)$. Therefore, hypothesis nine $\left(\mathrm{H}_{09}\right)$ was not supported. Students who learnt English writing by using StyleWriter achieved better scores in the vocabulary component in the writing assessment.

With regard to sentence structure in the essay writing assessment, the results showed that there was a significant difference between the control group $(M=2.13, S D=.730)$ and the experimental group $(M=3.40, S D=.621, t$ $(58)=7.24, p=.000<.05)$. As such, hypothesis ten $\left(\mathrm{H}_{010)}\right.$ was not supported.

The overall performance in English essay writing reflected the students' improvement in their writing skills. The table above (Table 3 ) shows that there was a significant difference between the scores of experimental group ( $M$ $=3.38, S D=.444)$ and the control group $(M=2.01 . S D=.402 ; t(58)=12.50, p=.00<.05)$. Thus, the last hypothesis $\left(\mathrm{H}_{011}\right)$ was not supported as using StyleWriter as a tool in the English writing class had helped students achieve better scores compared to those who used Microsoft Word.

\section{Discussion}

With technology-supported resources such as the computer, courseware and software easily available these days, the English teacher should choose the most appropriate software to help her achieve her objectives in the classroom.

This study showed that StyleWriter had an edge over Microsoft Word with regard to improving writing skills. There were higher scores by the experimental group using StyleWriter in the post-test overall performance. Even after the post-test period, the respondents continued practising their writing skills enthusiastically on their own, using both types of software to assist them. In other words, students had begun to be more responsible for their own learning (Wilson \& Thayalan, 2007; Jones, 2001). This observation concurred with findings that computer software helps students to learn according to individual speed, thus enjoying more autonomy as well as flexibility in carrying out their learning task (Volman, 2005). In this study, learners who utilized StyleWriter software became better writers compared to their counterparts who used Microsoft Word. The StyleWriter software gives useful feedback to the user to enable him to make changes based on the recommendations given, resulting in grammatical correctness, clarity, conciseness, and coherence. When students are able to learn from their mistakes, they will further improve their mastery of writing skills. Constructive and immediate feedback helps them to have a better understanding of grammar in writing and also enables them to get rid of poor writing habits (Lochtman, 2002). Students are able to reflect upon their errors and correct them when they can get an immediate response every time they write. The StyleWriter software is programmed with an abundance of linguistic information. It allows the students to discover different sub-skills of writing, such as grammar, spelling, style, as well as punctuation. Moreover, the linguistic information in the programme is pre-arranged in an-easy-to-use mode. In other words, it is user-friendly.

Based on the results of this study, teachers should encourage the use of suitable software for improving writing skills in the English class. Studies on progress made by students using new interactive technology show that it is not enough just to rely on conventional teaching methods. Students who are exposed to learning the English Language via computer-based methods are in an advantageous position to fully develop their potential in the basic language skills, viz. reading, writing, listening and speaking (Lee, 2002). 


\section{References}

Abu Naba'h, A. M. (2012). The impact of computer assisted grammar teaching on EFL pupils' performance in Jordan. International Journal of Education and Development using Information and Communication Technology (IJEDICT), 8(1), 71-90.

Boswood, T. (Ed.) (1997). New Ways of Using Computers in Language Teaching. Alexandria, VA: TESOL Inc.

Cohen, M., \& Riel, M. (1989). The Effect of Distance Audiences on Students. American Educational Research Journal, 26(2), 143-159.

Cononelos, T., \& Oliva, M. (1993). Using Computer Network to Enhance Foreign Language and Culture Education. Foreign Language Annals, 26(4), 234-252.

Decarrico, J. S. (2001). Vocabulary Learning and Teaching. In M. Celce-Murcia (Ed.), Teaching English as a Second or Foreign Language (3rd ed.). Boston: Heinle \& Heinle.

Eib, B. J., \& Cox, S. (2003). Integrating technology with teacher inquiry. Principal Leadership, 3, 54-58.

Mohamad, F., \& Amin, N. M. (2009). The Effectiveness of Customized Courseware in Teaching Grammar. Proceedings of the 2nd International Conference of Teaching and Learning (ICTL 2009) INTI University College, Malaysia. 1-12.

Fenrich, P. (2005). Creating instructional multimedia solutions: Practical guidelines for the real world. Santa Rosa, CA: Informing Science Press.

Figueredo, L., \& Varnhagen, C. K. (2006). Spelling and grammar checkers: Are they intrusive? British Journal of Educational Technology, 37, 721-732.

Forcier, R. C., \& Descy, D. D. (2008). Computer as an educational tool: Productivity and problem solving (5th ed.). Upper Saddle River, NJ: Pearson Merrill Prentice Hall.

Ghaith, G. (2002). Writing. Retrieved from http://nadabs.tripod.com/Ghaith-writing.html

Goesik, K. (2004). The process approach to teaching writing. Retrieved from http//www.dartmouth.edu/-writing/resources/tutor/pedagogy/process.html

Greany, S. J. (2007). Students Perceptions on Language Learning in a Technological Environment: Implications for the New Millennium. Language Learning and Technology, 20(7), 12-15.

Hartley, J., Sotto, E., \& Pennebaker, J. (2003). Speaking versus typing: A case-study of the effects of using voicerecognition software on academic correspondence. British Journal of Educational Technology, 34(1), $141-151$.

Haugland, S. W. (1992). The effect of computer software on pre-school children's development gains. Journal of Computing in Childhood Education, 3(1), 15-30.

Hegelheimer, V., Mills, D., Salzmann, A., \& Shetzer, H. (1996). World wide Web Activities That Work (and Why!). Paper presented at the International Conference of Teachers of English to Speakers of Other Languages, Chicago, $\quad$ Illinois. $\quad$ Retrieved from http://deil.lang.uiuc.edu/resources/Tesol/WWW_Activities.html

Hohmann, C. (1998). Evaluating and selecting software for children. Child Care Information Exchange, 123, 60-62.

Holdich, C. E., \& Chung, P. W. H. (2003). A 'computer tutor' to assist children develop their narrative writing skills: Conferencing with HARRY. International Journal of Human-Computer Studies, 59, 631-669.

Jones, J. (2001). CALL and the Teacher's Role in Promoting Learner Autonomy. CALL-EJ Online, 3(1). Retrieved from http://www.tell.is.ritsumei.ac.jp/callejonline/journal/3-1/jones.html

Lee, W. R. (2002). Language Teaching Games and Contests (2nd ed.). Oxford: Oxford University Press.

Lochtman, K. (2002). Oral correction feedback in the foreign language classroom: How iteffects interaction in analytic foreign language teaching. International Journal of Educational Research, 37(3), 271-283.

Mahdizadeh, A. (2006). Evaluate the English Course Books in Secondary School in Iran in Order To Enhance Teaching and Learning English Course. Journal of Educational Research in English Course, 77.

Mehrgan, K. (2012). Computer-Assisted Language Learning: A Panacea for Grammar Development. Advances in English Linguistics (AEL), 1(2), 25-29. 
Ministry of Education. (2001). Pembangunan Pendidikan 2001-2010. Kuala Lumpur: Kementerian Pendidikan Malaysia.

Nunan, D. (2003). Practical English Language Teaching. Singapore: McGraw Hill.

Ong, K. (2000). Website of Collaborative Projects: Operation Oceanwave II. Retrieved from http://geocities.com/Athens/Olympus/5276/tps.htm

Rowley, K., \& Meyer, N. (2003). The effect of a computer tutor for writers on student writing achievement. Journal of Educational Computing Research, 29(2), 169-187.

Schwienhorst, K. (2008). The 'third place' - virtual reality applications for secondary language learning. European Association for Computer Assisted Language, 1, 118-126.

Sharifah Maimunah Syed Zin, \& Lewin, K. M. (1993). Insight into science education: Planning and policy priorities in Malaysia. Laporan Kajian Bersama Kementerian Pendidikan Malaysia dan International Institute for Educational Planning, UNESCO Paris. IIPP's Printshop. University Press.

Volman, M. (2005). A variety of roles for a new type of teacher Educational technology and the teaching profession. Teaching and Teacher Education, 21, 15-31.

Williams, S. C. (2002). How speech-feedback and word-prediction software can help students write. Teaching Exceptional Children, 34(3), 72-78.

Wilson, D., \& Thayalan, V. (2007). The Role and Relevance of CALL. Retrieved from http://www3.telus.netlinguisticsissuesrolecall.html

Zhang, H. Y. (2007). Computer-assisted Elementary Chinese Learning for American Students. UCER, 4(5), $55-60$.

\section{Copyrights}

Copyright for this article is retained by the author(s), with first publication rights granted to the journal.

This is an open-access article distributed under the terms and conditions of the Creative Commons Attribution license (http://creativecommons.org/licenses/by/3.0/). 